\title{
Ochlerotatus albifasciatus in Rain Pools of Buenos Aires: Seasonal Dynamics and Relation to Environmental Variables
}

\author{
Sylvia Fischer ${ }^{+}$, M Cristina Marinone, Nicolás Schweigmann ${ }^{++}$ \\ Departamento de Ciencias Biológicas, Facultad de Ciencias Exactas y Naturales, Universidad de Buenos Aires, Pabellón II, \\ Ciudad Universitaria, C1428EHA Buenos Aires, Argentina
}

\begin{abstract}
The immature stages of Ochlerotatus albifasciatus develop in temporary pools. The present study aims at evaluating the seasonal dynamics of the aquatic stages of this mosquito, also analyzing the relationship among their presence and breeding success to some relevant climatic and environmental variables in the ephemeral rain pools of an urban park. Nineteen cohorts of $\mathrm{O}$. albifasciatus that developed synchronously after rain events were recorded in all seasons. The proportions of mosquito-positive pools were significantly higher during the fall-winter period than in the spring-summer months $(p<0.001)$. The presence of this mosquito species was positively related to the amount of rain $(p<0.001)$, whereas negatively correlated to air temperature $(p<0.05)$ within a 5.2 to $29.7^{\circ} \mathrm{C}$ range. The distribution of the number of cohorts per pool throughout the year was grouped (variance/mean: 3.96), indicating that these habitats were not equally suitable as breeding sites. The immature stages of $\mathrm{O}$. albifasciatus were detected in pools belonging to all of the categories of surface area, depth, duration, vegetation cover, and insolation. However, the proportion of pools where immature mosquitoes were detected was positively and significantly related to surface, depth, duration, and vegetation cover. On the other hand, the proportion of mosquito-positive pools was higher at an intermediate insolation degree. Our results suggest that although preimaginal stages were present in all seasons, high temperatures may be unfavorable to larval development, and substrate vegetation may regulate water temperature. The positive relationship between the proportion of mosquito-positive pools and pool size and duration might reflect a strategy of $\mathrm{O}$. albifasciatus to accomplish immature development.
\end{abstract}

Key words: urban rain pools - seasonal dynamics - breeding sites - Aedes - Culicidae - Buenos Aires - Argentina

Ochlerotatus albifasciatus (Macquart, 1838), formerly known as Aedes (Ochlerotatus) albifasciatus (Reinert 2000), is a wild floodwater mosquito widely distributed in the Southern region of South America, whose range extends from Southern Brazil and Bolivia to Tierra del Fuego (Bachmann \& Bejarano 1960, Prosen et al. 1960, Forattini 1965). Owing to its insistent attacks to man and domestic mammals (Forattini 1965), it is considered one of the most bothersome species of the region (Prosen et al. 1960). Early studies (Del Ponte \& Blaksley 1947, Manso Soto \& Martínez 1948, 1949) reported great abundance of adults as well as dense aggregations of immatures of this species in swampy areas and temporary aquatic habitats of Buenos Aires City. This mosquito has public health importance, since western equine encephalitis virus has been isolated from wild specimens caught during the outbreak registered in 1982-1983 (Mitchell et al. 1987), and under laboratory conditions it has proved to be a competent vector of this virus (Avilés et al. 1990).

This research was partially supported by a covenant endorsed by the Government of the City of Buenos Aires and the Faculty of Natural and Exact Sciences of the University of Buenos Aires. ${ }^{+}$Corresponding author. Fax: +54-11-4576-3384. E-mail: mosquito@bg.fcen.uba.ar

${ }^{++}$Researcher Consejo Nacional de Investigaciones Científicas y Tecnológicas, Buenos Aires, Argentina

Received 4 December 2001

Accepted 28 May 2002
The presence of immature stages of $O$. albifasciatus is associated with fluctuations in the flooding of aquatic habitats and rainfall amount (Gleiser et al. 2000a, Fontanarrosa et al. 2000). Females lay drought resistant eggs on the humid soils that surround temporary water bodies. Once embryonic development is complete, the eggs may enter diapause or hatch synchronously if covered by water for at least $3 \mathrm{~h}$ (Gleiser et al. 2000b). Larval development time shows a wide range of variation, from a minimum of 6 days in the summer (at a mean air temperature of $24^{\circ} \mathrm{C}$ ), up to 32 days in the winter (at $13^{\circ} \mathrm{C}$ ) (Fontanarrosa et al. 2000). The mortality of immature stages has been evaluated under laboratory conditions (Ludueña Almeida \& Gorla 1995), but field estimates have never been reported.

In Córdoba province, larvae and pupae have been detected during the fall-winter period (Almirón \& Brewer 1994), whereas in Buenos Aires province they have been found from spring through fall (Maciá et al. 1995). In the rain pools of parks in the city of Buenos Aires, the immature stages of this mosquito not only occur year-round (Fontanarrosa et al. 2000), but they are also the most abundant insects (Fischer et al. 2000).

The knowledge of the environmental factors regulating larval abundance and developmental success under natural conditions is fundamental to achieve effective mosquito control. The breeding sites of $O$. albifasciatus have been characterized as shallow temporary water bodies (Prosen et al. 1960), of variable size, either natural or artificial, with or without vegetation (Almirón \& Brewer 1996), generally located in floodplains (Forattini 1965). Several authors have referred to microhabitat characteris- 
tics associated with the presence of this species (Maciá et al. 1995, Ludueña Almeida \& Gorla 1995, Fontanarrosa et al. 2000). However, intensive studies of all larval habitats of a whole urban park have never been carried out. The present study analyzes the seasonal variations in the abundance of immature stages of $O$. albifasciatus as a function of climatic variables and the number of available habitats, and evaluates the association of characteristics of these pools with the presence of this species in a park of Buenos Aires City.

Study area - Buenos Aires is located in a humid temperate climatic region, with an annual mean temperature of $17.6^{\circ} \mathrm{C}$, annual mean relative humidity of $71 \%$, and annual mean of $1089 \mathrm{~mm}$ rainfall. Saavedra Park (343' 3 'S $58^{\circ} 29^{\prime} \mathrm{W}$ ) is located near the northern boundary of the city, lying on the piped course of Medrano Stream, which runs in a west-east direction on the main axis of the park. The irregular topography of the park, extending over approximately $13 \mathrm{ha}$, favors the formation of a great number of ephemeral pools after rain. These water bodies range from 0.1 to $600 \mathrm{~m}^{2}$ in surface area, 1 to $24 \mathrm{~cm}$ in depth, and last from one week to several months depending on the climatic conditions (Fischer et al. 2000). The substrate vegetation of the pools is mainly grass (Gramineae), which is periodically cut. Trees differentially shade the pools, some of which receive direct insolation throughout the day, others part of the day, whereas some remain in the shade most of the time. Owing to its location in a densely populated urban area, the park is extensively utilized for recreation and pools are highly disturbed. Owing to the proximity of pools, we assume that climatic variables, such as temperature and rainfall, affect them uniformly (Schneider \& Frost 1996).

\section{MATERIALS AND METHODS}

A total of 91 rain pools, identified in a preliminary phase of the study, were studied between June 1998 and May 1999. Maximum depth and surface area of each pool were determined weekly. Each pool was assigned to one of three insolation categories by estimating the proportion of exposure to direct sunlight throughout the day. The vegetation cover of the substrate was also assessed for each pool by differentiating among three categories: no grass cover, half of the pool surface covered by grass, and almost the whole substrate with vegetation cover. The number of opportunities on which each pool contained water was used to estimate its duration. In the summer and in the fall, the presence of water was controlled three times a week, in order to evaluate whether mosquito cohorts were able to complete their development in the different pools.

Immature mosquitoes were sampled weekly with a 350 $\mu \mathrm{m}$ mesh hand net, dragged along the bottom, on a single immersion that covered the longest axis of each pool. An $80 \mathrm{ml}$ plastic dipper was used to sample the shallowest pools. The number of samples collected was proportional to the surface of each water body (from 5 to 160 dips). During the summer, the samples were taken within five days after each rainfall in order to warrant the detection of all cohorts. Quantitative samples were taken from each pool from late August 1998 until the end of the study period. The samples were fixed in situ in $5 \%$ formaldehyde and subsequently stored in $80 \%$ ethanol. Immature mosquitoes were identified to species (Darsie 1985), but only the information on $O$. albifasciatus is herein analyzed.

The number of cohorts that developed throughout the study year in each individual pool and in the whole park were computed. The frequency distribution of the number of cohorts per pool throughout the year was analyzed in order to assess the suitability of the different pools as breeding sites. The variance to mean ratio was used to assess the distribution pattern of these frequencies. The Chi square test was used to assess whether the frequency distribution pattern deviates from randomness (Elliot 1977).

The total number of pools present on each sampling date was determined, and the proportion of mosquito $(O$. albifasciatus) positive pools at the beginning of each cohort was then calculated. These proportions were compared by means of a test of proportions for several independent samples (Fleiss 1981).

The relative abundance of larvae in each pool was calculated by multiplying the surface area times the mean number of larvae per dip. The relative abundance of each cohort was estimated by adding the larval abundance in every pool. The correlations between the relative abundance of larvae and the number of mosquito-positive pools (where immatures were detected) on the one hand, and with the number of successful pools (where larvae attain their fourth stage) on the other hand, were also computed.

The relationship between rain amount and the appearance of a cohort was explored in order to assess the threshold rainfall volume that triggers the development of new cohorts of $O$. albifasciatus. Rainfalls were grouped in three categories: $<10 \mathrm{~mm}, 10$ to $20 \mathrm{~mm}$, and $>20 \mathrm{~mm}$, and the proportion of rains that triggered cohort development in each category was calculated. These proportions were compared by means of a test for several independent, quantitatively ordered proportions (Fleiss 1981).

The number of mosquito-positive pools for each cohort was correlated to daily maximum and minimum air temperatures at the estimated time of egg hatching, as well as to the number of pools present on the date of first detection of each cohort. Meteorological records were provided by the National Meteorological Service for Villa Ortuzar Observatory (ca. $3 \mathrm{~km}$ from the park).

Larval survival - The breeding success of each cohort in each pool was assessed by recording the presence of fourth stage larvae. Although the presence of pupae provides a better estimation of survival, it was not documented for each brood. The seasonal proportions of successful pools were compared by means of a test for independent proportions (Fleiss 1981).

Aiming at comparing the success of cohorts raised under contrasting climatic conditions, the relative abundance of immature $O$. albifasciatus was assessed at their onset and at the fourth larval stage, both of a winter and a summer brood in all of the pools. Comparisons were made by means of a test of proportions for two independent samples (Fleiss 1981). 
Relationships with environmental variables - The relationships between the presence and the success of immature stages of this mosquito with surface, depth, habitat duration, vegetation cover of the substrate, degree of insolation, and weekly mean air temperature were studied. Several categories were established for each variable according to the following gradients: surface area: $0-1,1-10,10-100,>100 \mathrm{~m}^{2}$; depth: $1-5,6-10,11-15,>15 \mathrm{~cm}$; insolation: shade, half shade, open sun; vegetation cover: lacking, scarce, totally covered; and permanence: < 11, 11-20, 21-30, > 30 dates. Mean air temperatures were calculated for the 7-day period preceding the first sampling of each cohort. All variables were firstly screened by univariate analysis using tests for independent proportions (Fleiss 1981), whereas those that showed significant relationships to mosquito presence were included in a logistic regression analysis, performed with the S-plus V.6.02 statistical package (S-plus 2001). The logistic regression was performed by the sequential method, using the Chi square test to assess differences between models. In this case, no variables were included in the initial model, and new models were then elaborated by adding the variables one by one. The variable that produced the highest difference between the beforehand model and the actual model was included, and the process repeated for the remaining variables. The model was considered complete when any new variable produced no significant differences at a 0.01 probability level.

Only the dates of first detection of larvae for each cohort were included in the analysis, either for the whole year or seasonally grouped, in order to detect differences among climatic periods. The relative importance of the predictor variables of breeding success after colonization was assessed through a logistic regression analysis performed only on mosquito-positive pools. This analysis was not applied to the breeding success of the spring cohorts since these data did not meet the assumptions of the model.
The correlations between larval abundance and the evaluated environmental variables were also explored for two representative dates of the winter and the summer. The non-parametric Spearman rank correlation coefficient was used in all cases.

\section{RESULTS}

The number of temporary aquatic habitats was highly variable either among seasons or between consecutive weeks (Fig. 1). The maximum habitat availability was observed during the winter (median $=46$ pools), whereas in the spring of 1998 the number of aquatic habitats was minimal (median $=6$ pools). During the summer and the fall of 1999, the number of aquatic habitats was intermediate (with medians of 21 and 17 pools respectively).

Nineteen cohorts of $O$. albifasciatus were recorded in all seasons along the study year. The proportions of mosquito-positive pools reached higher values during the fall and the winter ( 0.55 and 0.53 respectively) than during the spring and the summer ( 0.23 and 0.33 respectively) (Fig. 1). The test of proportions failed to show significant differences between the spring and the summer. Except for two dates corresponding to the lowest proportions of pools that were positive for mosquitoes, the differences between the fall and the winter were non-significant either. During the spring-summer period the proportion of mosquito-positive pools was significantly lower $(\mathrm{p}<0.001)$ than in the fall-winter period (except for the already mentioned two dates).

The total relative abundance of larvae showed a positive correlation with the number of mosquito-positive pools $\left(\mathrm{r}_{\mathrm{s}}\right.$ $=0.85, \mathrm{p}<0.001, \mathrm{n}=14)$, and with the number of pools where larvae attained the fourth stage $\left(r_{s}=0.78, p<0.001, n\right.$ =14). Fifty-eight rain events exceeding $1 \mathrm{~mm}$ were recorded throughout the study year in Saavedra Park. Out of 29 rain events below $10 \mathrm{~mm}$, only a single rain $(6 \mathrm{~mm})$ originated a cohort of O. albifasciatus. Rainfalls between 10 and $20 \mathrm{~mm}$ produced mosquito broods in $45 \%(5 / 11)$ of the cases,

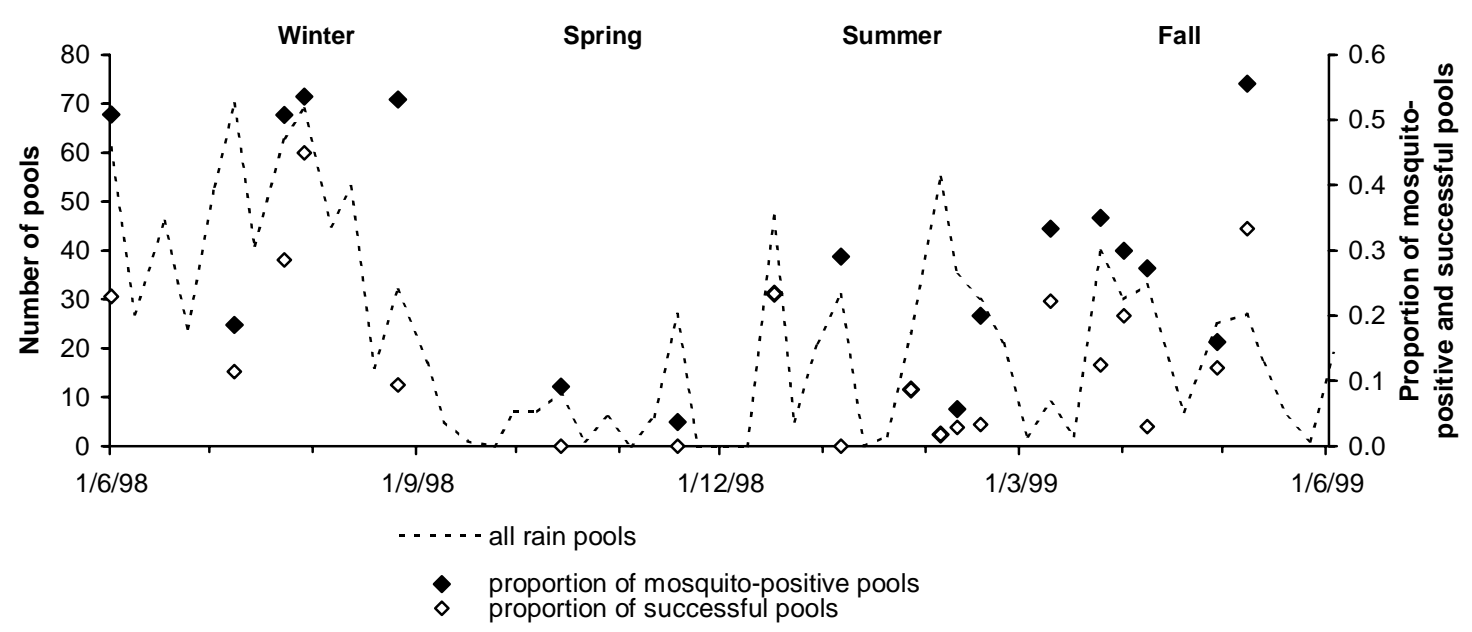

Fig. 1: weekly variation in the number of pools of the whole park and proportions of pools with mosquito larvae at the beginning of each cohort. 
whereas $72 \%$ (13/18) of the rainfalls exceeding $20 \mathrm{~mm}$ initiated the development of this species. Hence, our results indicate that the proportion of rainfalls that triggered cohorts of $O$. albifasciatus increases significantly for growing volumes of precipitation $(\mathrm{p}<0.001)$.

Egg hatching was detected in August at a minimum air temperature of $5.2^{\circ} \mathrm{C}$, and in March at a maximum of $29.7^{\circ} \mathrm{C}$. The total number of mosquito-positive pools was negatively and significantly $(\mathrm{p}<0.05)$ correlated to minimum $\left(r_{s}=-0.48\right)$, mean $\left(r_{s}=-0.48\right)$ and maximum air temperatures $\left(\mathrm{r}_{\mathrm{s}}=-0.47\right)$.

Larval survival - The accumulated number of mosquito-positive pools was 678 (each pool counted once for each cohort), and only $32 \%$ of these pools lasted until larvae reached the fourth stage. Similar percentages of successful pools were observed in the winter and in the fall (43\% and $41 \%$ respectively), as well as in the spring and in the summer (15\% and $14 \%$ respectively). The percentages of the winter-fall period showed significant differences with the spring-summer season $(p<0.001)$.

The total abundance of mosquito immatures was about five times lower in August than in March. However, while $13 \%$ of the immatures recorded at the onset of the development of the August cohort attained the fourth larval stage, only $4 \%$ of the individuals of the March cohort reached the last larval stage. Therefore, our data indicate that in the winter the proportion of surviving larvae was significantly higher than in the summer $(\mathrm{p}<0.001)$. Pool drying was responsible for the mortality of $21 \%$ of larvae in August, and 36\% in March, whereas the remaining mortality, which may be partially ascribed to a drastic decrease of the water volume, was similar in both seasons (65\% and $60 \%$ respectively).

Relationships with environmental variables - Immature stages of $O$. albifasciatus were detected, at least once in 51 out of the 91 studied pools. Cohorts that did not complete their preimaginal development were only found in eight water bodies, whereas in the 43 remaining pools the number of cohorts detected ranged from one to 16 . The maximum number of successful cohorts observed in a single pool was 13 . Most of the pools $(65 \%)$ where mosquitoes were never detected were ephemeral, and appeared less than five times during the study period. The frequency distribution of mosquito-positive pools for the whole park throughout the year, was grouped (3.96 variance/mean ratio, $\mathrm{p}<0.001$ ), indicating that these pools were not equally suitable as breeding sites for this species (Fig. 2).

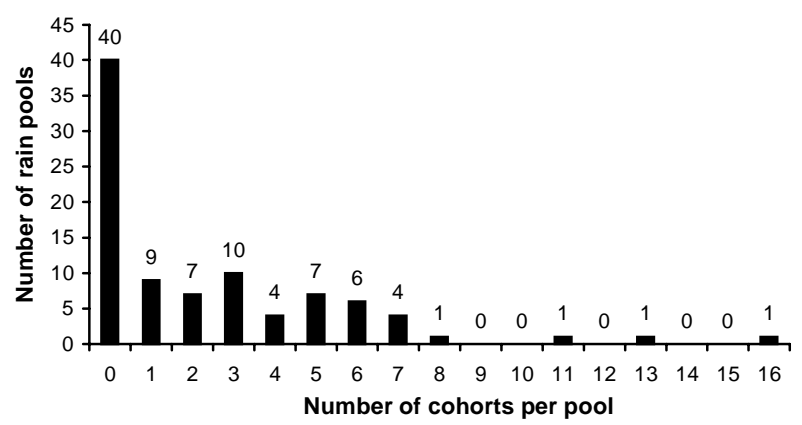

Fig. 2: frequency distribution of the number of cohorts detected in each pool of the park throughout the study year.
Immature stages of $O$. albifasciatus were found in every category of the evaluated pool variables. A significant increase in the presence of larvae, represented by the proportions of mosquito-positive pools and successful pools, was observed for growing values of surface area, depth, duration, and vegetation cover. The pools receiving intermediate levels of insolation were positive in a higher proportion than those pools getting either low or high levels of insolation. Although not significant in all cases, this trend also holds for the different seasons separately considered (Fig. 3). Differing from all other climatic periods, in the summer the degree of insolation was significantly related to the proportion of mosquito-positive pools, while dimensions were not.

The final models from the logistic regression analysis are given in the Table I. The presence of mosquito immatures showed a positive association with depth and vegetation cover, while a negative association with mean air temperature and insolation year-round. The relationships between mosquito presence and the selected variables differed among seasons. Pool dimensions were the only significant variables useful to predict the proportion of mosquito-positive pools in the winter and the spring, while substrate vegetation and temperature were also significant in the fall. On the other hand, during the summer season, the presence of $O$. albifasciatus was positively related to substrate vegetation and negatively associated to insolation. Breeding success was positively associated to surface area during the whole year, while in the summer and in the winter, mean air temperature was positively associated as well (Table II).

The relative abundance of larvae was positively correlated to the surface area and depth of the pools during the winter and the summer, whereas it only showed a negative correlation with the degree of insolation in the summertime (Table III). The abundance of $O$. albifasciatus immatures in the breeding sites failed to show significant correlations with any of the other evaluated variables.

\section{DISCUSSION AND CONCLUSIONS}

The year-round presence of immature stages of $O$. albifasciatus indicates that the climatic conditions of the city of Buenos Aires are not limiting to the development of this species. Thus, differences in habitat availability may be partially responsible for the detected seasonal fluctuations in the proportion of mosquito-positive pools. Both rainfall and temperature regimes influence the number and duration of pools in Saavedra Park. As already observed by Fischer et al. (2000), periods with similar accumulated rainfalls (winter and spring) but different temperatures, differed markedly in the number of rain pools formed, owing to a rapid absorption of water by the dry ground together with an accelerated evaporation at higher temperatures.

Because of its ease of measurement and its high correlation with larval abundance, we consider that the number of mosquito-positive pools is a good indicator of the abundance and success of the different broods. The higher quantity and proportion of mosquito-positive pools recorded during the winter correspond to a maximum availability of environments and to minimum temperatures, 
whereas the very low abundance observed in the spring of 1998 was clearly associated with a drought. The accumulated rainfall during this season was about half of the 30-year mean record for the spring in Buenos Aires city. Therefore, such climatic conditions may be considered critical for the development of this species, owing to the rapid desiccation of habitats (Fontanarrosa et al. 2000). The low abundances of immature stages of $O$. albifasciatus recorded during the summertime that followed the drought may be a consequence of the gradual decline of egg viability with time (Ludueña Almeida \& Gorla 1995) and/or of the absence of recent oviposition. Future investigations should evaluate whether the fall recolonization depends on the egg-bank remaining in the soil or on adult dispersal from adjacent areas.

In general, rains less than $10 \mathrm{~mm}$ did not trigger the development of new cohorts in the study area. Our results agree with the rainfall thresholds estimated for pools in the Buenos Aires University City by Fontanarrosa et al. (2000) for the same fall-winter season (16 to $17 \mathrm{~mm}$ ). However, for the spring-summer period the rainfall threshold required to initiate a cohort in Saavedra Park was lower than the value estimated by these authors $(25-30 \mathrm{~mm})$.

The extreme temperatures recorded during the winter season in Buenos Aires did not seem to limit egg hatching and preimaginal development. Likewise, results on
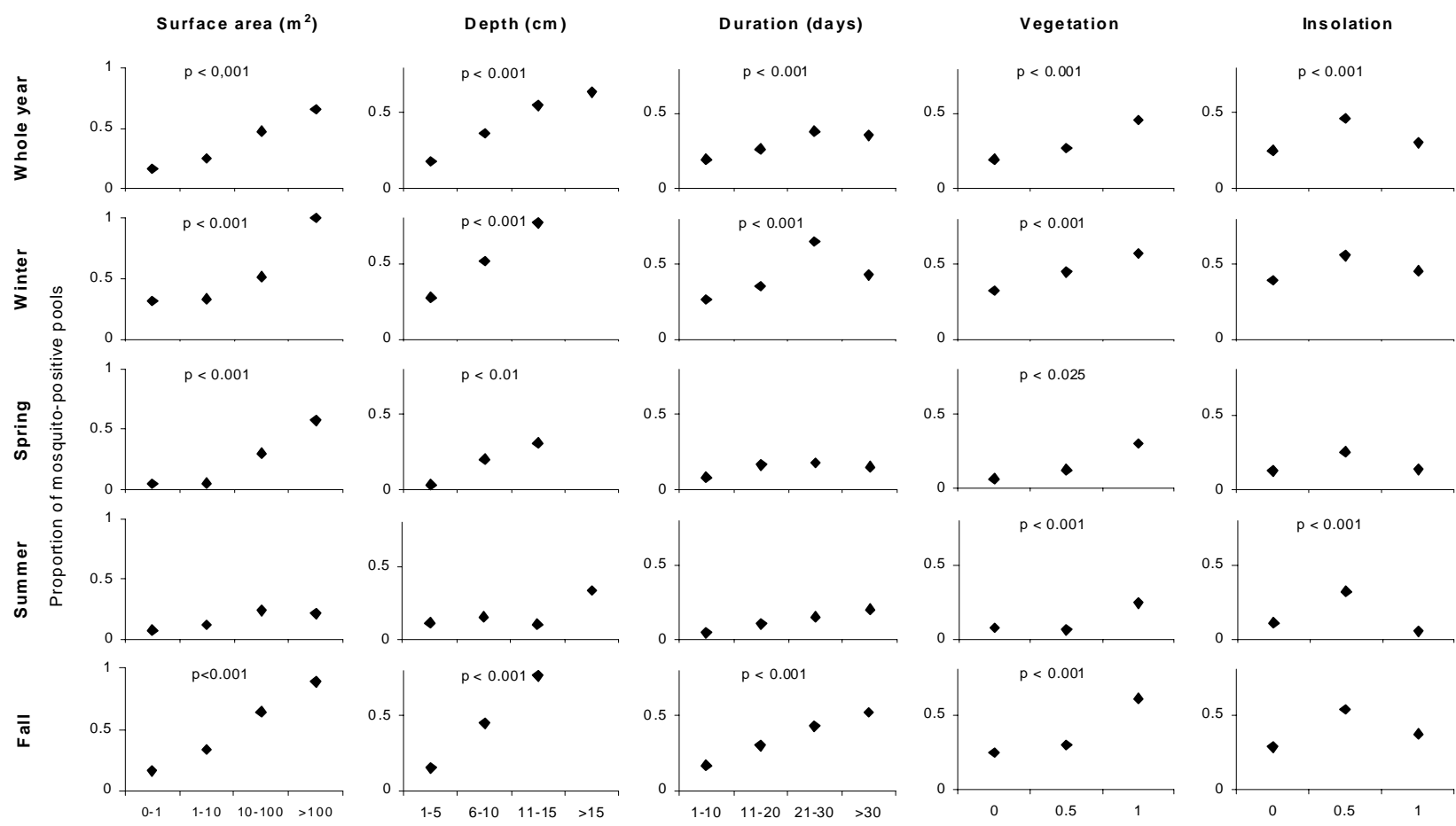

Fig. 3: proportions of mosquito-positive pools and successful pools for each category of surface area, depth, duration, vegetation cover, and insolation degree.

TABLE I

Logistic regression analysis of the mosquito-positive pools in Saavedra Park (OR-CI 95\%)

\begin{tabular}{|c|c|c|c|c|c|}
\hline Season & Depth & Temperature & Vegetation & Insolation & Surface area \\
\hline $\begin{array}{l}\text { Whole year } \\
(\mathrm{N}=678)\end{array}$ & $\begin{array}{c}2.4 \\
(1.9-3.2)\end{array}$ & $\begin{array}{c}0.8 \\
(0.8-0.9)\end{array}$ & $\begin{array}{c}4.2 \\
(2.6-7.0)\end{array}$ & $\begin{array}{c}0.5 \\
(0.8-0.3)\end{array}$ & \\
\hline $\begin{array}{l}\text { Winter } \\
(\mathrm{N}=233)\end{array}$ & $\begin{array}{c}3.7 \\
(2.7-5.4)\end{array}$ & & & & \\
\hline $\begin{array}{l}\text { Spring } \\
(\mathrm{N}=85)\end{array}$ & & & & & $\begin{array}{c}3.8 \\
(1.7-8.5)\end{array}$ \\
\hline $\begin{array}{l}\text { Summer } \\
(\mathrm{N}=161)\end{array}$ & & & $\begin{array}{c}11.0 \\
(3.0-40.3)\end{array}$ & $\begin{array}{c}0.1 \\
(0.0-0.5)\end{array}$ & \\
\hline $\begin{array}{l}\text { Fall } \\
(N=199)\end{array}$ & $\begin{array}{c}4.0 \\
(2.3-6.9)\end{array}$ & $\begin{array}{c}0.8 \\
(0.7-0.9)\end{array}$ & $\begin{array}{c}5.0 \\
(2.2-11.3)\end{array}$ & & \\
\hline
\end{tabular}

OR: odds ratio; $\mathrm{CI}$ : confidence interval 
TABLE II

Logistic regression analysis of the pools where Ochlerotatus albifasciatus reached the fourth larval stage in Saavedra Park (OR-CI 95\%)

\begin{tabular}{lcc}
\hline Season & Temperature & Surface area \\
\hline Whole year & & 2.6 \\
$(\mathrm{~N}=217)$ & & $(1.8-3.8)$ \\
Winter & 3.1 & 2.2 \\
$(\mathrm{~N}=100)$ & $(1.5-6.5)$ & $(1.2-3.9)$ \\
Summer & 2.5 & \\
$(\mathrm{~N}=23)$ & $(1.1-6.1)$ & \\
Fall & & 3.9 \\
$(\mathrm{~N}=81)$ & & $(1.9-8.1)$ \\
\hline
\end{tabular}

OR: odds ratio; $\mathrm{CI}$ : confidence interval

TABLE III

Significant correlations between larval abundance of Ochlerotatus albifasciatus and environmental variables of the pools in Saavedra Park

\begin{tabular}{rcc}
\hline Variable & $\mathrm{R}($ Spearman $)$ & $\mathrm{p}$ \\
\hline $\begin{array}{c}\text { Winter cohort }(\mathrm{N}=17) \\
\text { surface area } \\
\text { depth }\end{array}$ & 0.81 & $\mathrm{p}<0,001$ \\
Summer cohort $(\mathrm{N}=14)$ & 0.83 & $\mathrm{p}<0,001$ \\
surface area & & \\
depth & 0.89 & $\mathrm{p}<0,001$ \\
insolation & 0.62 & $\mathrm{p}<0,05$ \\
& -0.53 & $\mathrm{p}<0,05$ \\
\hline
\end{tabular}

populations of $O$. albifasciatus from Córdoba province suggest that cold temperatures and short day lengths preclude neither larval development (Almirón et al. 2000) nor gonotrophic activity (Fava et al. 2001). These findings are not surprising given that the distribution of this species extends as far south as to the cold-temperate island of Tierra del Fuego (Bachmann \& Bejarano 1960). Nevertheless, our result conflicts with the conclusions of a study performed in Buenos Aires province, where high water level fluctuations at minimum winter temperatures $\left(6.3^{\circ} \mathrm{C}\right)$ were considered to limit hatching (Maciá et al. 1995).

The negative relationship between the presence of $O$. albifasciatus and the insolation degree during the summertime, as shown by the results from the logistic regression and by the negative correlation between mosquito abundance and the degree of exposure to sun, suggest that the high temperatures of this season in Buenos Aires city $\left(30^{\circ} \mathrm{C}\right.$ mean maximum) are unfavorable to the egg hatching of this species. These observations are coincident with those reported by Maciá et al. (1995) for Buenos Aires province. On the other hand, the logistic regression showed the existence of a positive relationship between larval survival and air temperature in the summer, which suggests that in pools where hatching occurs (mostly shaded and/or having substrate vegetation), water temperatures are within the favorable range for this spe- cies. Anyhow, such conclusion deserves experimental corroboration.

Two of our observations corroborate the opportunistic reproductive strategy of $O$. albifasciatus: the massive mortality of immature stages (mainly owing to the disappearance of breeding sites before the preimaginal development can be accomplished), and the detection of immature stages within all categories of size, duration, insolation, and vegetation cover of the studied pools.

The frequency distribution of the number of cohorts occurring in every single pool (Fig. 2) indicates that some of them have a higher chance to become breeding sites than others do, thus suggesting that some environmental variables favor the presence of this mosquito. For the whole study period, the presence of immatures of this species was related to increasing pool size categories, abundant substrate vegetation, and decreasing levels of exposure to the sun. The positive association found between mosquito presence and pool size (given by depth or surface area), for the whole year, as well as for all seasons except the summer, could be explained by a selection by mosquito females of those breeding sites that maximize the survival probabilities of their progeny, given the extremely ephemeral nature of the studied pools.

Differing from the results reported by Maciá et al. (1995) on breeding sites near La Plata (Buenos Aires province), where this species seems to prefer sunny environments, but in coincidence with the observations made by Fontanarrosa et al. (2000) on pools of the city of Buenos Aires, the present study of a larger number of pools indicates that the highest abundance of larvae occurred in shaded pools, specially in the summer season. The positive relationship between the presence of preimaginal mosquitoes and increasing substrate vegetation may be explained by a shade effect within the pool that reduces water temperature to a certain extent (Fischer, unpublished observations), also increasing the availability of shelter from potential predators.

Although both the richness and the abundance of predatory insects increased in the summertime in the studied environments (Fischer et al. 2000), the low abundance of immature $O$. albifasciatus recorded during this season was unlikely associated with the presence of predators, since high numbers of immature Culex spp. were simultaneously collected in these pools (Fischer et al. 2000). Future research should evaluate whether the seasonal fluctuations in the abundance of $O$. albifasciatus have some kind of relation to the presence of different predatory insects and algae observed in the pools. Coming studies should also assess the population dynamics of this species at a broader geographic scale within the urban district. The knowledge of the microhabitat conditions that favor the presence of $O$. albifasciatus will permit a better understanding of the environmental requirements of this species, and therefore the development and application of better control methods.

\section{ACKNOWLEDGEMENTS}

To Mariela Nieves for her field assistance, and to Dr Diana Rubel for her statistical help. To the two anonymous reviewers whose comments greatly improved an early version of this paper. 


\section{REFERENCES}

Almirón WR, Brewer ME 1994. Immature stages of mosquitoes (Diptera: Culicidae) collected during the autumn-winter period in Cordoba Province, Argentina. Mem Inst Oswaldo Cruz 89: 625-628.

Almirón WR, Brewer ME 1996. Classification of immature stage habitats of Culicidae (Diptera) collected in Córdoba, Argentina. Mem Inst Oswaldo Cruz 91: 1-9.

Almirón WR, Ludueña Almeida FF, Brewer M 2000. Relative abundance and gonotrophic status of Aedes albifasciatus (Diptera: Culicidae) during the autumn-winter period in Córdoba Province, Argentina. J Med Entomol 37: 16-20.

Avilés G, Sabattini MS, Mitchell CJ 1990. Peroral susceptibility of Aedes albifasciatus and Culex pipiens complex mosquitoes (Diptera: Culicidae) from Argentina to western equine encephalitis virus. Rev Saú Púb (São Paulo) 24: 265-269.

Bachmann AO, Bejarano JFR 1960. Dispersión de mosquitos en la Patagonia (Dipt. Culicidae-Culicinae). Neotrópica 6: 70-71.

Darsie Jr RF 1985. Mosquitoes of Argentina. Part I. Keys for identification of adult females and fourth stage larvae in English and Spanish (Diptera, Culicidae). Mosq Syst 17: 153-253.

Del Ponte E, Blaksley JC 1947. Importancia sanitaria de los Culicidae de la ciudad de Buenos Aires. Prensa Méd Argentina 34: 821-824.

Elliot JM 1977. Some Methods for the Statistical Analysis of Samples of Benthic Invertebrates, 2nd ed., Sci Publ 25, Fresh Biol Assoc UK, Titus Wilson \& Son Ltd., Kendal, 160 pp.

Fava FD, Ludueña Almeida FF, Almirón WR, Brewer M 2001. Winter biology of Aedes albifasciatus (Diptera: Culicidae) from Córdoba, Argentina. J Med Entomol 38: 253-259.

Fischer S, Marinone MC, Fontanarrosa MS, Nieves M, Schweigmann N 2000. Urban rain pools: seasonal dynamics and entomofauna in a park of Buenos Aires. Hydrobiologia 441: 45-53.

Fleiss JL 1981. Statistical Methods for Rates and Proportions, John Wiley \& Sons, New York, 312 pp.

Fontanarrosa MS, Marinone MC, Fischer S, Orellano PW, Schweigmann N 2000. Effects of flooding and temperature on Aedes albifasciatus development time and larval density in two rain pools at Buenos Aires University City. Mem
Inst Oswaldo Cruz 95: 787-793.

Forattini OP 1965. Entomologia Médica, 2. Culicini: Culex, Aedes e Psorophora, Univ. São Paulo, São Paulo, 506 pp.

Gleiser RM, Gorla DE, Schelotto G 2000a. Population dynamics of Aedes albifasciatus (Diptera: Culicidae) south of Mar Chiquita Lake, Central Argentina. J Med Entomol 37: 2126.

Gleiser RM, Urrutia J, Gorla DE 2000b. Effects of crowding on populations of Aedes albifasciatus larvae under laboratory conditions. Entomol Exp Applic 95: 135-140.

Ludueña Almeida FF, Gorla DE 1995. The biology of Aedes (Ochlerotatus) albifasciatus Macquart, 1838 (Diptera: Culicidae) in Central Argentina. Mem Inst Oswaldo Cruz 90: 463-468.

Maciá AA, García JJ, Campos RE 1995. Bionomics of Aedes albifasciatus and A. crinifer (Diptera: Culicidae) and its natural enemies in Punta Lara, Buenos Aires. Neotrópica 41: 43-50.

Manso Soto AE, Martínez A 1948. Estudios sobre mosquitos de la Ciudad de Buenos Aires. Misión Estudios Patología Regional Argentina 19: 39-49.

Manso Soto AE, Martínez A 1949. Estudios sobre mosquitos de la Ciudad de Buenos Aires. Misión Estudios Patología Regional Argentina 20: 53-61.

Mitchell CJ, Monath TP, Sabattini MS, Daffner JF, Cropp CB, Calisher CH, Darsie Jr RF, Jakob WL 1987. Arbovirus isolations from mosquitoes collected during and after the 1982-1983 epizootic of Western Equine Encephalitis in Argentina. Am J Trop Med Hyg 36: 107-113.

Prosen AF, Martínez A, Carcavallo RU 1960. La familia Culicidae (Diptera) en la ribera fluvial de provincia de Buenos Aires. An Inst Med Regional 5: 101-113.

Reinert JF 2000. New classification for the composite genus Aedes (Diptera: Culicidae: Aedini), elevation of subgenus Ochlerotatus to generic rank, reclassification of the other subgenera, and notes on certain subgenera and species. J Am Mosq Control Assoc 16: 175-188.

Schneider DW, Frost TM 1996. Habitat duration and community structure in temporary ponds. $J \mathrm{~N} \mathrm{Am} \mathrm{Benth}$ Soc 15: 64-86.

S-Plus V.6.02 for Windows 2001. Guide to Statistics, Vol. 1, Insightful Corporation, Seattle. 
774 O. albifasciatus in Rain Pools of Buenos Aires - Sylvia Fischer et al. 